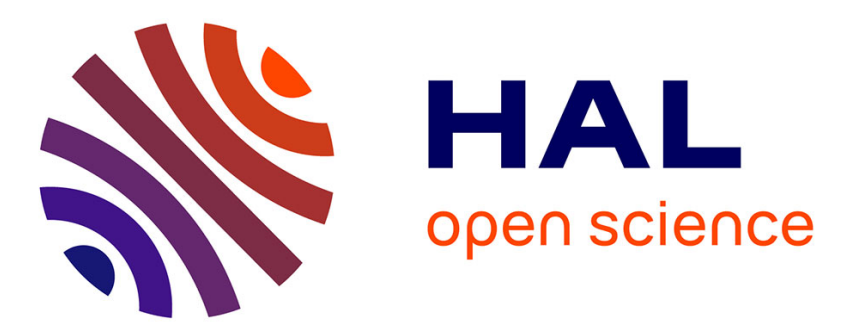

\title{
Gold/Silica thin film for biosensors application : Metal Enhanced Fluorescence
}

\author{
A. Regnier, T. Mangeat, H. Benalia, C. Elie-Caille, Ch. Pieralli, B. Wacogne
}

\section{To cite this version:}

A. Regnier, T. Mangeat, H. Benalia, C. Elie-Caille, Ch. Pieralli, et al.. Gold/Silica thin film for biosensors application: Metal Enhanced Fluorescence. Laser Physics, 2010, 20 (3), pp.591-595. 10.1134/S1054660X10050178 . hal-00446128

\section{HAL Id: hal-00446128 \\ https://hal.science/hal-00446128}

Submitted on 15 Apr 2021

HAL is a multi-disciplinary open access archive for the deposit and dissemination of scientific research documents, whether they are published or not. The documents may come from teaching and research institutions in France or abroad, or from public or private research centers.
L'archive ouverte pluridisciplinaire HAL, est destinée au dépôt et à la diffusion de documents scientifiques de niveau recherche, publiés ou non, émanant des établissements d'enseignement et de recherche français ou étrangers, des laboratoires publics ou privés. 


\title{
Gold/Silica Thin Film for Biosensors Applications: Metal Enhanced Fluorescence
}

\author{
A. Renier ${ }^{a}$, T. Mangeat ${ }^{a}$, H. Benalia ${ }^{a}$, C. Elie-Caille ${ }^{b}$, C. Pieralli ${ }^{a}$, and B. Wacogne ${ }^{a}$ * \\ ${ }^{a}$ Optics Department, FEMTO-ST Institute, UFR ST, 16, route de Gray, 25030 Besançon cedex, France \\ ${ }^{b}$ Clinic-Innovation Proteomic Platform, FEMTO-ST Institute, 32, avenue de l'Observatoire, \\ 25044 Besançone cedex, France \\ *e-mail: bruno.wacogne@univ-fcomte.fr
}

\begin{abstract}
The work described here concerns the fabrication of cost-effective biosensors that permit to amplify a fluorescence signal without a complex nano-structuration of the surface. The idea is to put to profit the natural pseudo nano-structuring that is observed when depositing metallic layers by various micro-fabrication techniques. This new architecture consists of a glass substrate. A gold film is deposited on the top of it and a silica layer onto the gold. A dye (Cy5) is then absorbed onto the surface and the fluorescence intensity is measured. This intensity depends on the distance between the dye and the metal. It also depends on the properties of the metallic film. The goal of the work is to determine which gold deposition method leads to the highest fluorescence amplification and which silica thickness is required to achieve this amplification.
\end{abstract}

\section{INTRODUCTION}

Over the past decade optical biosensors have been largely developed to study biomolecular interactions. The most important characteristics of biosensors are specificity and sensitivity. Specificity strongly depends on the biospecific interface of biosensors. Biorecognition processes and non-specific interactions depend on the (i) surface of material, (ii) chemical functionalization, and (iii) biomolecular grafting. Sensitivity depends not only on the (bio)-functionalizations but also on the biosensor architecture and transduction elements. Nowadays, techniques based on Surface Plasmon Resonance (SPR) [1] are largely used because they present a high degree of sensitivity. In this case, local change in the refractive index inside the evanescent-field region of the plasmon mode shifts the resonance angle. An angular shift of approximately $1 \times$ $10^{-4}$ degree corresponds typically to the adsorption of a biological film of about $100 \mathrm{pg} / \mathrm{cm}^{2}[2,3]$.

SPR is not the only method for studying biochemical interactions. A lot of optical techniques based on fluorescence [4], Fluorescence Resonance Energy Transfer (FRET) [5], or Surface Enhanced Raman Spectroscopy (SERS) [6] are widely investigated. A very large panel of solutions already provides high specificity and sensitivity (classical fluorescent probes, two photon detection, nanosphere, etc.). The new challenge in fluorescence detection is to enhance the fluorescence signal and to produce highly directional signals for new highly sensitive biosensors with high signal to noise ratio (optical nanoantenna [7], Surface
Plasmon Coupled Emission (SPCE) [8, 9]). Biosensors based on immunofluorescence techniques permits to detect a biologic entity trapped on a surface and revealed by a fluorescent complementary entity. The sensitivity of these biosensors generally relies on an optimized bio-functionalization of their surface. However, it is possible to improve the sensitivity of such sensors in an intrinsic manner by acting directly on the internal structure of the biosensor, regardless of the strategy of bio-functionalization. This physical structuring of the biosensor allows a global orientation of the fluorescent dipoles, improving the efficiency of fluorescence light collection. This can be called fluorescence amplification. Techniques currently developed are based on a nano-structuring of the surfaces by means of nano-spheres [10] or nano-machining by Focused Ions Beam (FIB) [11]. These methods, although efficient, are still too expensive to allow their use on a routine basis.

The goal of the studies described here consists in fabricating cost-effective biosensors that permit to amplify a fluorescence signal without nano-structuring the surface. The idea is to put to profit the natural pseudo nano-structuring that is observed when depositing metallic layers by various micro-fabrication techniques. This new architecture consists of a glass substrate, a gold layer and a silica layer. Recently, we have shown that such a structure allows amplifying the fluorescence signal issued from a dye adsorbed onto the bio-sensor surface [12]. Indeed, the fluorescence intensity depends on the distance "dye-metal" and on the nature of the gold layer. The goal of the work is to determine which gold deposition method leads to the 


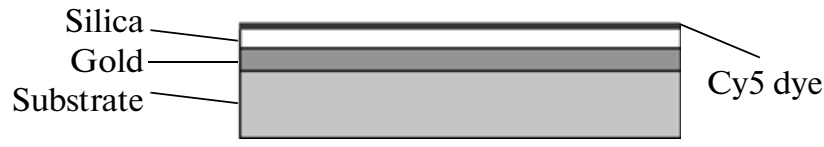

Fig. 1. Schematic representation of the gold/silica fluorescence sensor.

highest fluorescence amplification and which silica thickness is required to achieve this amplification.

In the next part of this paper we present the process used to fabricate the gold/silica biochips as well as some characterizations of the devices obtained with different deposition techniques. Section 3 concerns experimental results of fluorescence amplification as well as attempts made to theoretically explain our results. Then, a conclusion will draw our attention to some perspective to be given to this work.

\section{FABRICATION PROCESS OF GOLD/SILICA THIN FILMS}

\subsection{Fabrication Process of the Gold Films}

As previously mentioned, this new architecture consists of a glass substrate, gold and silica layers superimposed. A dye (Cy5) is then adsorbed onto the surface and the fluorescence intensity is measured (Fig. 1). This intensity depends on the distance "dyemetal" and on the nature of the gold layer. At first, a $2 \mathrm{~nm}$ thick chromium layer is deposited on a $\mathrm{SiO}_{2}$ wafer (diameter: $13 \mathrm{~mm}$, thickness: $0.17 \mathrm{~mm}$ ) with plasma sputtering technology to improve the adherence of gold to the substrate.

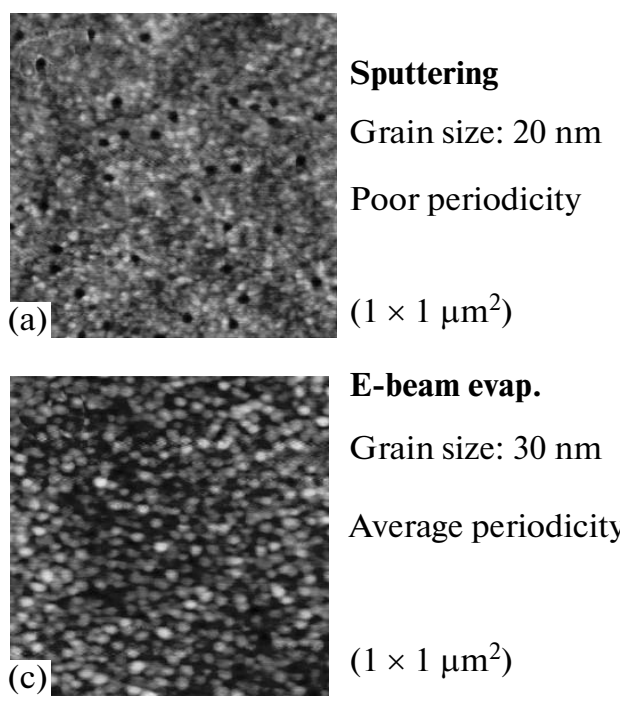

Concerning the deposition of the gold thin films, four deposition techniques were employed: sputtering, electroforming, electron beam evaporation and Joule effect evaporation. The main deposition parameters for each of the deposition technique are listed below.

- Sputtering: current: $600 \mathrm{~mA}$, pressure: $8 \times$ $10^{-3}$ mbar, deposition rate: $0.21 \mu \mathrm{m} / \mathrm{min}$.

- Electroforming: $\mathrm{pH}=4$, temperature: $55^{\circ} \mathrm{C}$, current density: $0.5 \mathrm{~A} / \mathrm{dm}^{2}$, deposition rate: $0.2 \mu \mathrm{m} / \mathrm{min}$.

- Electron beam evaporation: rotation: $5 \mathrm{rpm}$, temperatur: $20^{\circ} \mathrm{C}$, pressure: $2 \times 10^{-6}$ mbar, deposition rate: $9 \mathrm{~nm} / \mathrm{min}$.

- Joule effect evaporation: current 16 A, pressure: $4 \times 10^{-6}$ mbar, deposition rate: $18 \mathrm{~nm} / \mathrm{min}$.

\subsection{Atomic Force Microscopy Characterization of the Gold Films}

Using these four techniques, gold films of about $40 \mathrm{~nm}$ were deposited onto the silica substrates. The surface roughness was then analyzed with AFM techniques. The AFM used was a Nanoscope III (Veeco, Santa Barbara, CA). Imaging was performed in contact mode using NPS-oxide sharpened silicon nitride probes. The surface topographies of a $40 \mathrm{~nm}$ thick gold thin films are presented in Figs. 2a-2d. The images size is $1 \times 1 \mu^{2}$. We measured two topography characteristics: size of the grains (lateral dimension) and Root Mean Square (RMS : vertical dimension). It appears that, except for electroforming, gold film exhibit a pseudo-periodic structure with grains of various diameters. The grain sizes were estimated by image processing and the RMS was measured by means of a high pass filtering in the Fourier domain.
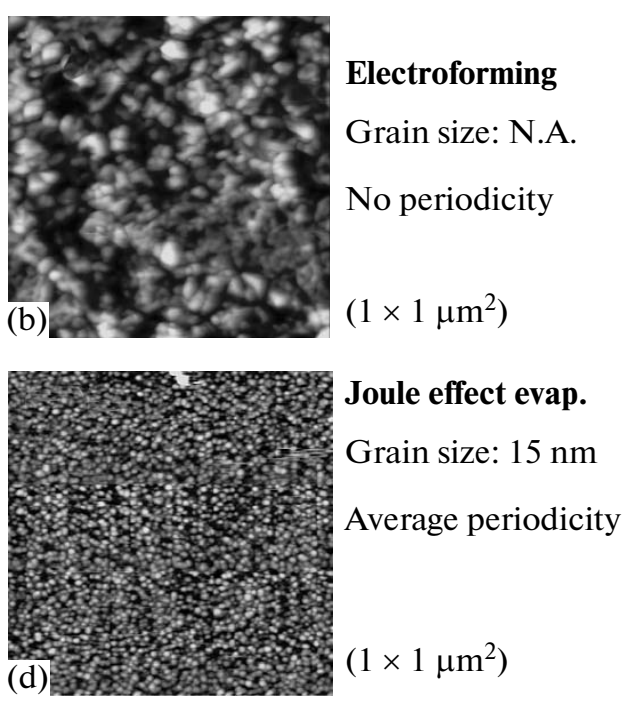

Fig. 2. Atomic Force Microscope picture of gold surfaces obtained by: (a) sputtering, (b) electroforming, (c) electron beam evaporation, and (d) Joule effect evaporation. Pictures size is $1 \times 1 \mu \mathrm{m}^{2}$. 


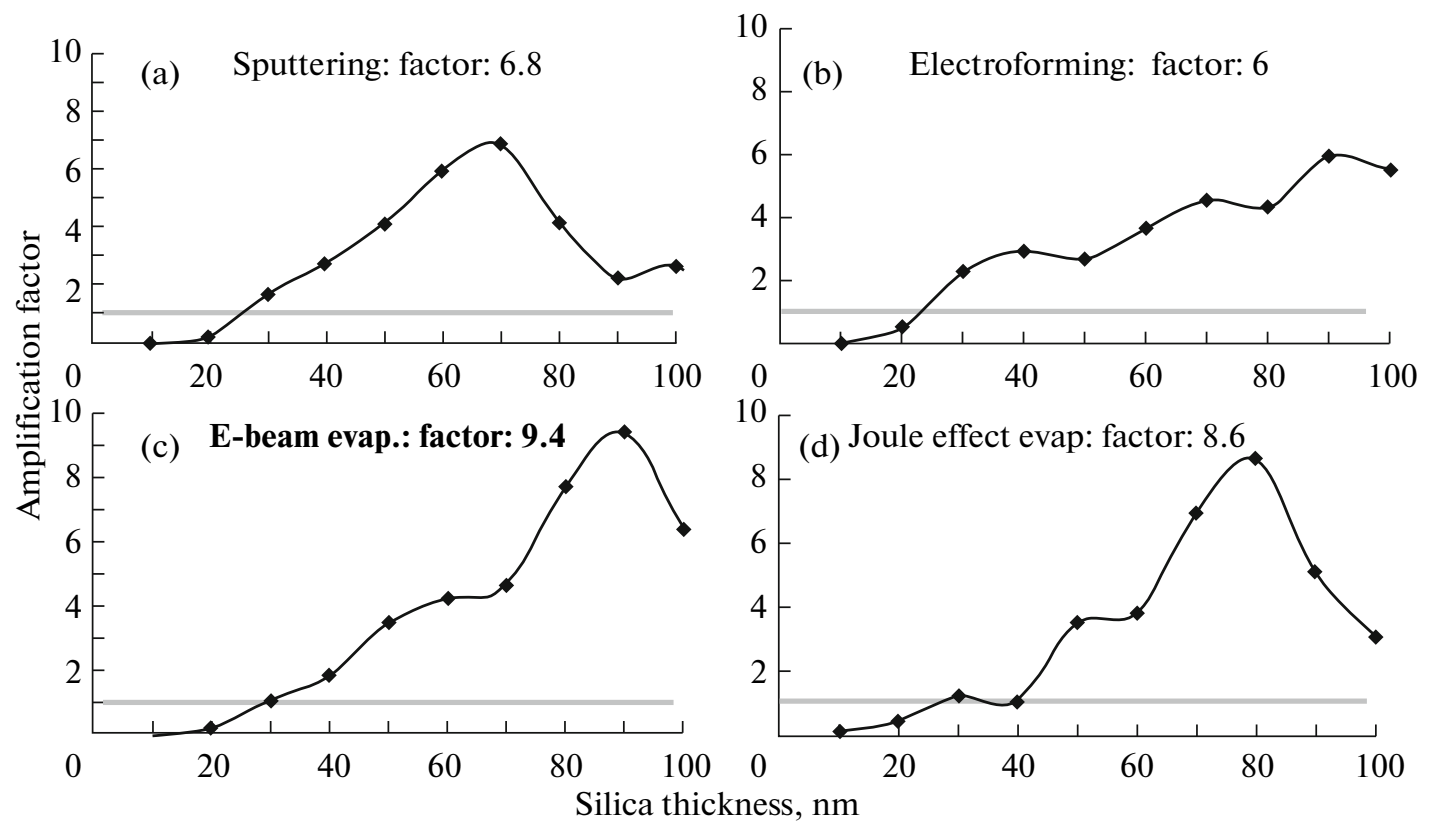

Fig. 3. Amplification factors obtained as a function of the silica thickness. (a) Sputtering, (b) electroforming, (c) electron beam evaporation, and (d) Joule effect evaporation. The amplification factor is defined by the ratio (fluorescence intensity on gold/silica chip)/(fluorescence intensity on silica chip).

Apparently, no correlation can be found between the grain size and the RMS. Note that films obtained by electroforming do not present clear pseudo-periodicity. AFM measurements can be summarized as follows:

- Sputtering: grain size: $20 \mathrm{~nm}, \mathrm{RMS}=8 \mathrm{~nm}$, poor periodicity.

- Electroforming: grain size: N.A., RMS $=17 \mathrm{~nm}$, no periodicity.

- Electron beam evaporation: grain size: $30 \mathrm{~nm}$, $\mathrm{RMS}=3 \mathrm{~nm}$, average periodicity.

- Joule effect evaporation: grain size: $15 \mathrm{~nm}$, $\mathrm{RMS}=16 \mathrm{~nm}$, average periodicity.

\subsection{Fabrication Process of the Silica Like Films and Characterization}

After gold of different nature has been deposited on a collection of silica substrates, thin silica-like films were deposited by means of Plasma Enhanced Chemical Vaporization Deposition (PECVD) according the following conditions: temperature $24^{\circ} \mathrm{C}$; gas mixture $\mathrm{SiH}_{4}, \mathrm{~N}_{2} \mathrm{O}$, and Ar with the respectively gas flow 13 , 51 , and $35 \mathrm{sccm}$; total pressure in the reactor $0.13 \mathrm{mBar}$ and power $54 \mathrm{~W}$ at $150 \mathrm{kHz}$. The deposition rate is about $660 \AA / \mathrm{min}$ with these experimental conditions. For each type of gold PECVD silica films with thicknesses varying from 10 to $100 \mathrm{~nm}$ were deposited. It must be noted that the silica like material obtained with this technique exhibits a good adherence on gold. Therefore, no more pre-coating with $\mathrm{Cr}$ or $\mathrm{Ti}$ is required.
First of all, we tried to estimate the stoechiometry of the silica-like films. An X Photoelectron Spectroscope was used and we deduced the following composition of the thin films: $\mathrm{SiON}_{0.5} \mathrm{C}_{0.05}$. This composition led us to call our thin films "silica-like." At present, the presence of carbon is not understood. Ellipsometric measurements were conducted in order to measure the refractive index of the silica-like material. The use of a Jobin Yvon UVISEL ellipsometer led to the following value of the refractive index $n=1.58$ (no imaginary part).

\subsection{Cy5 Dye Adsorption}

The fluorophore used was Cyanine 5 also called Cy5. $62 \mu \mathrm{g}$ of Cy5 were diluted into $4 \mathrm{ml}$ of pure ethylic alcohol. Chips were immerged in the solution for $20 \mathrm{~min}$. They were then gently dried and were therefore ready for use.

\section{EXPERIMENTAL RESULTS AND THEORETICAL ATTEMPTS}

As mentioned above, silica thin films can be employed to reduce the strong quenching that occurs when a fluorophore is close to a metallic surface [13, 14]. Also, the control of the silica thickness allows optimizing the distance between the metallic surface and the fluorophore in order to enhance the fluorescence signal [15]. These effects have been studied with our biochip, with Cy5 dye deposited by sedimentation on the top of gold/silica chips with several silica thick- 

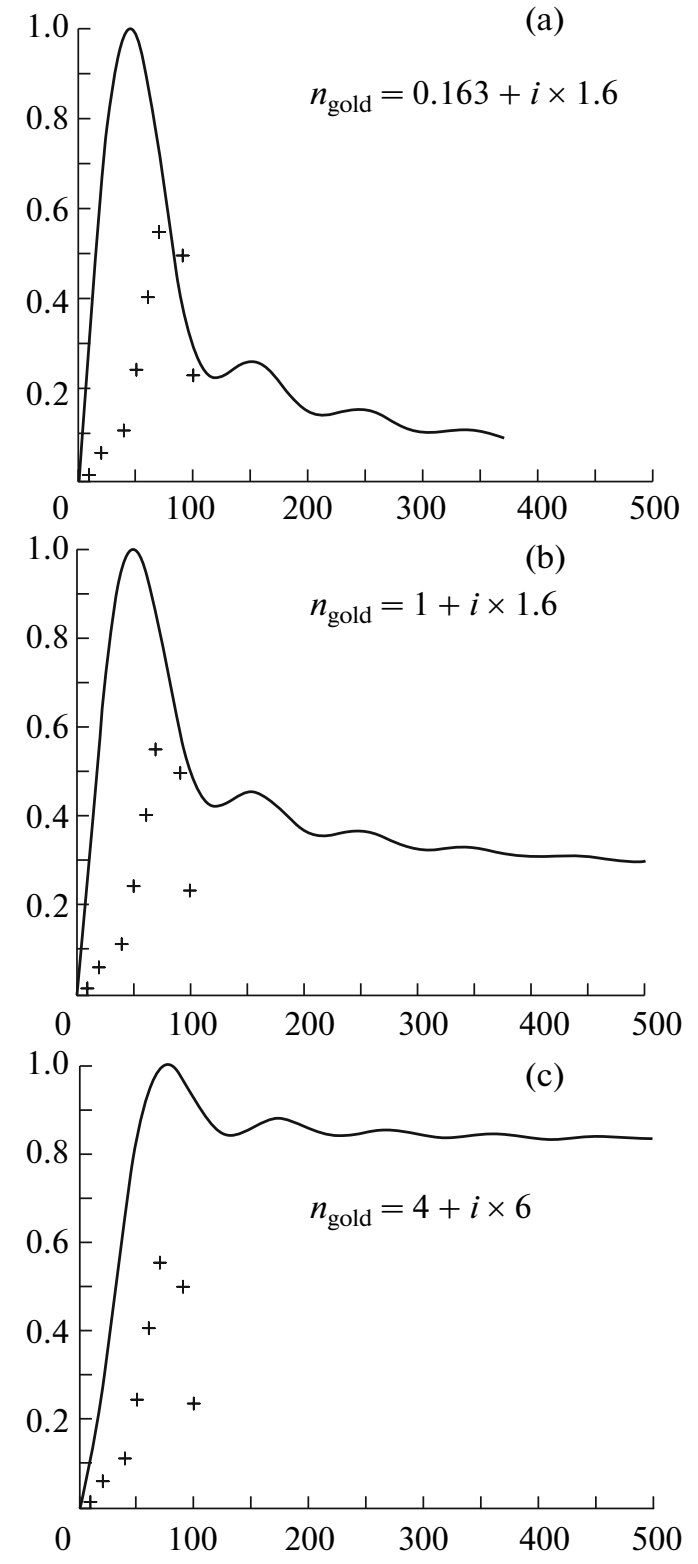

Fig. 4. An attempt to theoretically predict the fluorescence intensity. (a) Fitting the real part of the gold refractive index, (b) fitting both the real and the imaginary part, and (c) completely illogical values. The refractive index of the silica film is $n=1.58$.

nesses. Then, the fluorescence intensity was recorded for each silica-like thickness and for each type of gold. Fluorescence intensity was then compared to the fluorescence intensity obtained with a pure silica chip (without any gold layer). Therefore, we calculated an "amplification factor" for each chip configuration.

\subsection{Experimental Results}

In the work presented in reference [12], we used an Olympus IX71 fluorescence optical microscope, which was quite heavy. In the present work, we used the new ESE fluorescence module (FLUO SENS DD $005 \mathrm{f6}$ ). It is a compact, stand alone, confocal fluorescence measurement unit. Measurements were made slightly out of focus in order to compensate for inhomogeneity of the Cy5 coating.

Figures $3 a-3 d$ show the amplification factor observed with gold obtained by sputtering, electroforming, electron beam evaporation and Joule effect evaporation respectively. Curves represent the amplification factors as a function of the silica-like thickness.

It is clearly seen that quenching dramatically reduces the fluorescence intensity when the dye is close to the metal surface (below $20 \mathrm{~nm}$ silica thickness). The most interesting result concerns the fact that with gold obtained by means of electron beam evaporation, the amplification factor is almost 10 (to be compared to almost 4 in our previous work [12]). This amplification factor is obtained with a $90 \mathrm{~nm}$ thick silica film. This result shows that it is possible to amplify a fluorescence signal without complicated and expensive nano-structuring of the sensor surface. Of course, the amplification factor is still low, but large enough for many biomedical applications.

\subsection{Theoretical Attempts}

We tried to better understand the behavior of this sensor architecture. To this end, we used a theoretical model developed in our laboratory a few years ago [16]. The idea was to use this model in order to fit the complex value of the refractive index of the gold layer. Indeed, it is well known that the complex refractive index of gold thin films depends not only on the deposition technique which is used but also on the deposition parameters employed. The result is shown in Fig. 4. For Fig. 4a, we used the value of the real part of the gold refractive index usually found in the literature and we tried to fit the imaginary part. Obviously, we did not succeed. After, for Fig. 4b, we tried to fit both real and imaginary parts of the refractive index. In this case, we did not obtain a better result. Then (Fig. 4c), we tried to used completely illogical values. Here, the result was not worse than before.

In fact, the theoretical model we used in order to predict the fluorescence amplification of our devices does not work. Indeed, the model was devoted to the fluorescence properties of a fluorophore in the vicinity of a single atomic gold layer. Our sensor structure does not involve a single atomic layer but a $40 \mathrm{~nm}$ thick gold film. Furthermore, we recall that the physical structuring of our sensor allows a global orientation of the fluorescent dipoles, improving the efficiency of fluorescence light collection. The nano-structuring of the gold films is not taken into account in our model. We are currently working in collaboration with specialists in near field optics modeling in order to set up a more realistic model. 


\section{CONCLUSIONS}

In this paper, we have presented a new gold/silica biochip for biosensors applications. The control of the quenching as well as the enhancement of the fluorescence has been demonstrated. For a silica layer thickness of $90 \mathrm{~nm}$, an enhancement factor of 9.4 was achieved with gold deposited by electron beam evaporation.

Current work is oriented toward two different applications. The influence of the surface roughness of the gold layer on the fluorescence enhancement is currently studied. It implies a theoretical description of the system in order to identify which direction should be given to our work. This should lead to higher sensitivity biosensors. At the same time, we are looking at the possibility of using our gold/silica chips in Surface Plasmon Coupled Emission (SPCE). It was proved in literature that SPCE could increase the fluorescence signal by a factor of up to 1000 . In this technique, the high directionality of fluorescence emission may greatly improve the signal to noise ratio. Furthermore, the angular position of the SPCE emission peak is strongly wavelength dependent and it is possible to use SPCE as a spectrally resolving technique. In other words, this directional detection allows using different fluorophores at a same time without the use of additional dispersive elements. The idea behind is to fabricate a biosensor that can be used to detect several biochemical reactions simultaneously.

\section{REFERENCES}

1. R. L. Rich and D. G. Myszka, Curr. Opin. Biotechnol. 11, 54 (2000).
2. E. Stenberg, B. Persson, H. Roos, and C. Urbaniczky, J. Colloid Interface Sci. 143, 513 (1991).

3. W. D. Wilson, Science 295, 2103 (2002).

4. W. C. Chan, D. Maxwell, X. Gao, R. E. Bailey, M. Han, and S. Nie, Curr. Opin. Biotechnol. 13, 40 (2002).

5. I. L. Medintz, A. R. Clapp, and H. Mattoussi, Nat. Mater. 2, 630 (2003).

6. D. A. Stuart, A. J. Haes, A. D. McFarland, S. Nie, and R. P. Van Duyne, Proc. SPIE Intern. Soc. Opt. Eng. 5327, 60-73 (2004).

7. S. Kühn, U. Håkanson, L. Rogobete, and V. Sandoghdar, Phys. Rev. Lett. 97, 017402 (2006).

8. C. D. Geddes, I. Gryczynski, J. Malicka, Z. Gryczynski, and J. R. Lakowicz, J. Fluoresc. 14, 119 (2004).

9. G. Wintera and W. L. Barnes, App. Phys. Lett. 88, 051109 (2006).

10. A. Pereira, D. Grojo, Ph. Delaporte, M. Chaker, D. Guay, and M. Sentis, Small 4, 572 (2008).

11. E. M. Goldys, A. Barnett, F. Xie, K. Drozdowicz-Tomsia, I. Gryczynski, E. G. Matveeva, Z. Gryczynski, and T. Shtoyko, App. Phys. 89, 265 (2007).

12. T. Mangeat, C. Elie-Caille, M. Perrin, W. Boireau, C. Pieralli, and B. Wacogne, Laser Phys. 19, 252 (2009).

13. P. Anger, P. Bharadwaj, and L. Novotny, Phys. Rev. Lett. 96, 113002 (2006).

14. G. Schneider, G. Decher, N. Neramourg, R. Praho, M. V. Werts and M. Blanche-Desce, Nano Lett. 6, 530 (2006).

15. J. Zhang and J. R. Lakowicz, Opt. Express 15, 2598 (2007).

16. T. Pagnot, D. Barchiesi, D. Van Labeke, and C. Pieralli, Opt. Lett. 22, 120 (1997). 